\title{
PERANCANGAN SISTEM INFORMASI AKUNTANSI REVENUE CYCLE DAN INVENTORY PADA PT XYZ
}

\author{
Arta M. Sundjaja; Yudhi Kristianto \\ Jurusan Komputerisasi Akuntansi, Fakultas Ilmu Komputer, Bina Nusantara University \\ Jln. K.H Syahdan No 9, Palmerah, Jakarta Barat 11480 \\ asundjaja@binus.edu; you_2zz@yahoo.com
}

\begin{abstract}
PT XYZ is a trading company in electronic equipment distributor of Philips, that needs accounting information system in developing system ongoing manual to be a computerized one. The research method used is analysis method and object-oriented analysis and design (OOAD). The data collecting is through survey of the ongoing system and also interview based on supported theories, which gathered from the books about analysis and system design. The design method is through designing suggested system model. The expected result is sales accounting information system, cash income, and other feature to help PT XYZ in doing events. The result from this research is this information system application could help reduced data searching error transaction by employees. Especially, in reducing errors caused by data record error transaction by employees. This is purposed to every employee could be more focus in doing the events and more responsible in every acts.
\end{abstract}

Keywords: accounting information system, sales, cash income, purchasing, cost

\begin{abstract}
ABSTRAK
PT. XYZ merupakan perusahaan dagang yang bergerak dibidang distributor alat-alat listrik merk Philips, yang sangat memerlukan Sistem Informasi Akuntansi dengan mengembangkan sistem yang sedang berjalan saat ini yakni secara manual menjadi terkomputerisasi. Metodologi penelitian yang digunakan adalah dengan Metode Analisa dan Perancangan Sistem Berbasis Orientasi Objek (OOAD). Metode pengumpulan data dilakukan survei pada sistem yang sedang berjalan serta wawancara juga didasarkan pada teori yang mendukung, yang diperoleh dari buku yang berkaitan dengan analisa dan perancangan sistem. Metode perancangan yang dilakukan dengan merancang model sistem yang diusulkan. Hasil yang dicapai adalah sistem informasi akuntansi penjualan, penerimaan kas dan persediaan yang membantu PT. XYZ dalam menjalankan kegiatan usahanya. Kesimpulan dari hasil penelitian yang telah dilakukan adalah aplikasi sistem informasi ini dapat membantu meminimalkan terjadinya kesalahan pencatatan data transaksi oleh karyawan. Terutama dalam hal meminimalisasikan kesalahan yang terjadi akibat kesalahan pencatatan data transaksi oleh karyawan, hal ini bertujuan agar setiap karyawan dapat lebih fokus dalam melaksanakan kegiatannya dan lebih bertanggung jawab atas segala tindakan yang dilakukan.
\end{abstract}

Kata kunci: sistem informasi akuntansi, penjualan, penerimaan kas, pembelian, pengeluaran kas. 


\section{PENDAHULUAN}

Dalam perkembangan ekonomi pasca krisis moneter yang terjadi pada akhir tahun 2008 hingga pertengahan tahun 2009, menyebabkan persaingan dalam bisnis elektronik semakin berat. Untuk menghadapi persaingan dalam bisnis elektronik diperlukan dukungan berupa prosedur, sumber daya manusia, teknologi pendukung, informasi untuk membantu manajemen perusahaan dalam mengambil keputusan.

PT. XYZ merupakan sebuah perusahaan yang bergerak di bidang penjualan dan pemasangan alat-alat listrik. Saat ini PT. XYZ mengalami beberapa permasalahan dalam revenue cycle dan persediaan, adapun beberapa permasalahan yang dihadapi adalah perusahaan beberapa kali tidak dapat memenuhi atau terlambat mengirim order yang diterima karena ketidaktersediaan barang di gudang, pemilik perusahaan tidak mendapatkan informasi mengenai jumlah penjualan kotor yang update per bulan, dan terkadang terjadi dobel penagihan terhadap pelanggan. Melihat permasalahan yang dihadapi oleh PT. XYZ, manajemen PT. XYZ memerlukan sebuah sistem informasi untuk mendukung proses penjualan dan penerimaan kas.

Oleh karena itu penulis berusaha menganalisis dan merancang sistem informasi yang dapat membantu pihak managemen untuk menyelesaikan masalah-masalah yang dihadapi dalam proses penjualan dan penerimaan kas. Ruang lingkup dalam pembahasan penelitian ini adalah proses penjualan, penerimaan kas dan persediaan barang jadi pada PT. XYZ. Secara khusus, penelitian ini akan dibatasi pada proses berikut.

Secara khusus, tesis ini akan dibatasi pada rumusan masalah, yaitu (1) penjualan dan penerimaan kas: pencatatan order yang dilakukan oleh pelanggan, pengiriman barang order kepada pelanggan, penagihan atas order yang telah dikirim kepada pelanggan, penerimaan kas atas tagihan yang dilakukan kepada pelanggan; (2) retur penjualan: membuat surat retur barang, membuat surat jalan retur penjualan barang, membuat memo debet, tidak membahas penghapusan pencatatan piutang, pengakuan hutang atas tagihan dari supplier atas stock defect; (3) perhitungan Harga Pokok Penjualan; (4) tidak membahas mengenai PPN (Pajak Pertambahan Nilai).

Adapun tujuan yang dapat diperoleh adalah menganalisa sistem informasi akuntansi penjualan, penerimaan kas, dan persediaan pada PT XYZ, merancang sistem informasi akuntansi penjualan, penerimaan kas, dan persediaan pada PT XYZ sesuai dengan kebutuhan informasi guna mendukung kegiatan perusahaan, serta memberikan solusi terhadap permasalahan yang muncul pada PT XYZ. Adapun manfaat yang dapat diperoleh adalah mendefinisikan permasalahan yang muncul dalam proses bisnis PT XYZ, membantu menyelesaikan permasalahan yang muncul dalam proses bisnis PT XYZ, serta membantu meningkatkan kinerja PT XYZ dalam proses penjualan dan penerimaan kas.

\section{PEMBAHASAN}

\section{Pengertian Sistem Informasi Akuntansi}

Menurut Jones \& Rama (2006), Sistem Informasi Akuntansi adalah bagian dari Sistem Informasi Manajemen (SIM) yang menyediakan informasi mengenai akuntansi dan keuangan, seperti informasi-informasi lainnya yang didapatkan dari proses transaksi akuntansi rutin. 


\section{Tujuan Siklus Pendapatan}

Menurut Wilkinson (2000), Tujuan utama dari siklus pendapatan adalah untuk memfasilitasi pertukaran barang dan jasa dengan sejumlah uang tertentu dengan pelanggan. Berikut adalah sasaran dari siklus pendapatan secara umum, yaitu (1) untuk mencatat pesanan pelanggan secara cepat dan tepat; (2) untuk memverifikasikan bahwa pelanggan layak mendapatkan kredit; (3) untuk mengirimkan produk pada tanggal yang telah disetujui; (4) untuk melakukan penagihan atas produk atau jasa secara tepat pada waktunya dan dengan prosedur yang benar; (5) untuk mencatat dan mengklasifikasikan penerimaan kas secara cepat dan tepat; (6) untuk memposting penjualan dan penerimaan kas kedalam akun pelanggan yang tepat dalam jurnal khusus penjualan dan penerimaan kas; (7) untuk mengamankan produk sampai dikirim; (8) untuk mengamankan kas sampai disetor.

\section{Dokumen dalam Siklus Penjualan}

Menurut Wilkinson (2000), berikut ini adalah dokumen-dokumen yang dibutuhkan dalam siklus pendapatan perusahaan dagang: (1) sales order, adalah form formal yang memiliki banyak copy yang dipersiapkan dari customer; (2) shipping notice, biasanya merupakan copy dari sales order atau dokumen pengiriman terpisah yang berfungsi sebagai bukti bahwa barang telah dikirimkan; (3) sales invoice, sdalah dokumen yang dikirimkan ke pelanggan untuk menyatakan berapa jumlah penjualan; (4) remitance advice, adalah dokumen yang menunjukkan jumlah penerimaan kas dari pelanggan; (5) deposit slip, adalah dokumen yang menyertai penyetoran kas ke bank; (6) back order, adalah dokumen yang dipersiapkan ketika kuantitas dari persediaan tidak mencukupi sales order; (7) credit memo, adalah dokumen yang memungkinkan pengurangan kredit pelanggan untuk pengembalian penjualan atau penyisihan penjualan; (8) credit application, adalah sebuah form yang dipersiapkan ketika pelanggan baru mengajukan kredit; (9) cash register receipt, adalah form yang digunakan oleh retailer untuk mencerminkan kas yang diterima.

\section{Teori Analisis dan Perancangan Sistem Informasi}

\section{Pengertian Object Oriented Analysis and Design (OOAD)}

Menurut Mathiassen et al. (2000), “Objek adalah suatu entitas dengan identitas, keadaan (tingkatan hidup) dan tingkah laku” (p. 4). Objek merupakan dasar dalam OOAD, setiap objek digambarkan secara terkelompok karena ada beberapa objek yang memiliki sifat atau fungsi yang sama yang dikenal dengan istilah class. Class adalah suatu deskripsi atas kumpulan objek yang saling menggunakan struktur, pola tingkah laku dan atribut secara bersama-sama. Notasi yang digunakan dalam OOAD adalah UML (Unified Modelling Langguage). UML hanya digunakan sebagai notasi dan bukan sebagai metode dalam pemodelan.

Menurut Mathiassen et al. (2000), metode analisis dan perancangan berorientasi objek tersebut mempunyai empat aktivitas utama yaitu (1) system definition, adalah deskripsi dari sebuah sistem terkomputerisasi yang dijelaskan dalam bahasa sehari-hari; (2) rich picture, rich adalah gambaran informal yang mewakili pengertian akan situasi dari si pembuat; (3) factor, yaitu functionality (fungsi yang mendukung tugas-tugas aplikasi domain), aplication domain (bagian dari organisasi yang mengadministrasikan, mengawasi atau mengontrol sebuah problem domain), condition (suatu kondisi dimana sistem yang akan dikembangkan dan digunakan), technology (teknologi yang digunakan untuk mengembangkan sistem dan teknologi sistem yang akan dijalankan), object (objek utama dari problem domain), responsibility (sistem secara keseluruhan bertanggung jawab dalam hubungan dengan konteknya); (4) analisis problem domain, adalah bagian dari konteks yang dikelola, dimonitor, atau dikontrol oleh sistem. tujuan dari analisis problem domain adalah untuk mengidentifikasi dan membuat suatu model dari problem domain, aktivitas dalam problem domain. modeling terdiri dari classes, structure dan behaviour. 


\section{Analisis Aplication Domain}

Menurut Mathiassen et al. (2000), application domain adalah suatu organisasi yang mengolah, mengawasi atau mengendalikan suatu problem domain. Aktivitas di dalam analisis application domain terdiri dari usage (kegunaan), function (fungsi), dan interface (tampilan). Architectural design adalah merancang arsitektur sebuah mesin. Tujuan dari architectural design adalah untuk menusun sebuah sistem yang terkomputerisasi. Hasil dari architectural design adalah susunan untuk sebuah komponen sistem dan proses, didalam architectural design terdapat beberapa aktivitas terdiri dari criteria, component, dan process.

Menurut Mathiassen et al. (2000), model component adalah bagian dari sistem yang mengimplementasikan problem domain. Hasil dari mendesain model component adalah class diagram dari model component. Menurut Mathiassen et al. (2000, p252), function component adalah bagian dari sistem yang mengimplementasikan kebutuhan functional. Hasil dari mendesain function component adalah class diagram dengan operasi dan spesifikasi operasi yang kompleks.

Menurut Mathiassen et al. (2000, p252), sequence diagram adalah gambaran bagaimana objek-objek berinteraksi satu dengan yang lainnya melalui event-event yang dilakukan dari suatu use case atau operasi. DBMS adalah sebuah sistem perangkat lunak yang memungkinkan pemakai untuk mendefinisi, membuat, memelihara, dan mengontrol akses ke basisdata.

Proses bisnis sistem yang berjalan pada PT. XYZ adalah sebagai berikut. Pertama pelanggan datang, lalu sebelum pelanggan memesan barang sales akan mengecek status pelangan terlebih dahulu didalam data pelanggan. Jika pelanggan tidak aktif, pelanggan harus melakukan pendaftaran terlebih dahulu. Jika pelanggan aktif, sales akan mengecek piutang pelanggan terlebih dahulu berdasarkan data piutang pelanggan. Jika limit pelanggan habis, pelanggan harus melunasi pembayaran terlebih dahulu, jika masih ada limit sales akan langsung memproses sales order. Dalam memproses sales order, sales akan mengecek stok barang kepada bagian gudang berdasarkan data barang. Jika stok ada, sales akan langsung memproses sales order. Jika stok tidak ada sales akan mengkonfirmasi kepada pelanggan bahwa stok kurang dan sales akan membuat sales order menjadi tiga rangkap, satu rangkap akan diarsip oleh KaBag Penjualan, oleh pelanggan dan akan diarsip oleh KaBag Gudang. Setelah sales membuat sales order, sales akan memberikan sales order kepada KaBag Penjualan untuk dicek daftar pelanggan, daftar piutang jatuh tempo dan diotorisasi terlebih dahulu.

Setelah KaBag Gudang mendapatkan sales order, KaBag Gudang akan membuat surat perintah kerja rangkap 2, yaitu rangkap satu akan diarsip sendiri dan satunya akan diberikan kepada bagian gudang. Setelah bagian gudang menerima surat perintah kerja, Bagian Gudang akan mengecek persediaan barang menurut data barang. Jika barang tidak mencukupi, Bagian Gudang akan konfirmasi ke KaBag Gudang, dan jika barang ada bagian gudang akan menyediakan barang menurut surat perintah kerja, dan menyiapkan pengiriman barang dan akan mengarsip surat perintah kerja yang kedua.

Setelah bagian gudang menyiapkan barang, KaBag Penjualan akan membuat faktur dan akan mengotorisasinya, faktur dibuat menjadi tiga rangkap. Rangkap pertama akan diarsip dan akan menyerahkan faktur rangkap kedua kebagian Gudang. Setelah membuat faktur dan mengotorisasinya, KaBag Penjualan akan membuat surat jalan untuk diberikan kepada bagian pengiriman dan akan mengarsipnya, KaBag Penjualan juga akan memberikan faktur rangkap tiga, dan bagian pengiriman akan membuat laporan pengiriman barang dan bagian pengiriman akan mengirim barang kepada pelanggan. Setelah pelanggan menerima pesanannya, pelanggan akan menerima sales order ketiga dan akan menerima barang beserta faktur ketiga. Setelah itu Pelanggan akan mengecek barang berdasarkan faktur ketiga. 
KaBag Penjualan akan mengecek jatuh tempo tagihan menurut data pelanggan, Jika pelanggan ada yang jatuh tempo, KaBag Penjualan akan mengkonfirmasi untuk ditagih. KaBag Gudang akan membuat surat tagih rangkap dua, yang satu akan diarsip sendiri dan yang kedua akan diberikan kepada sales untuk mengkonfirmasi kepada pelanggan.

Pelanggan akan menerima surat tagih rangkap dua, dan pelanggan akan membayar sesuai dengan surat tagih. Pelanggan dapat membayar secara tunai dan juga cek, setelah itu pelanggan akan mengotorisasi surat tagih. Sales akan mengkonfirmasi kepada pelanggan dan meminta tanda tangan dari pelanggan untuk bukti pembayaran, sales akan membuat bukti pembayaran rangkap dua, satu akan diarsip untuk sendiri dan yang kedua akan diberikan kepada KaBag Akuntansi Dan Keuangan. Setelah menerima Bukti Pembayaran dari sales, KaBag Akuntansi Dan Keuangan akan mengotorisasi dan akan mengarsip bukti pembayaran rangkap dua.

Seperti yang sudah dideskripsikan diatas, proses revenue cycle pada PT. XYZ dapat digambarkan sebagai berikut (Gambar 1).

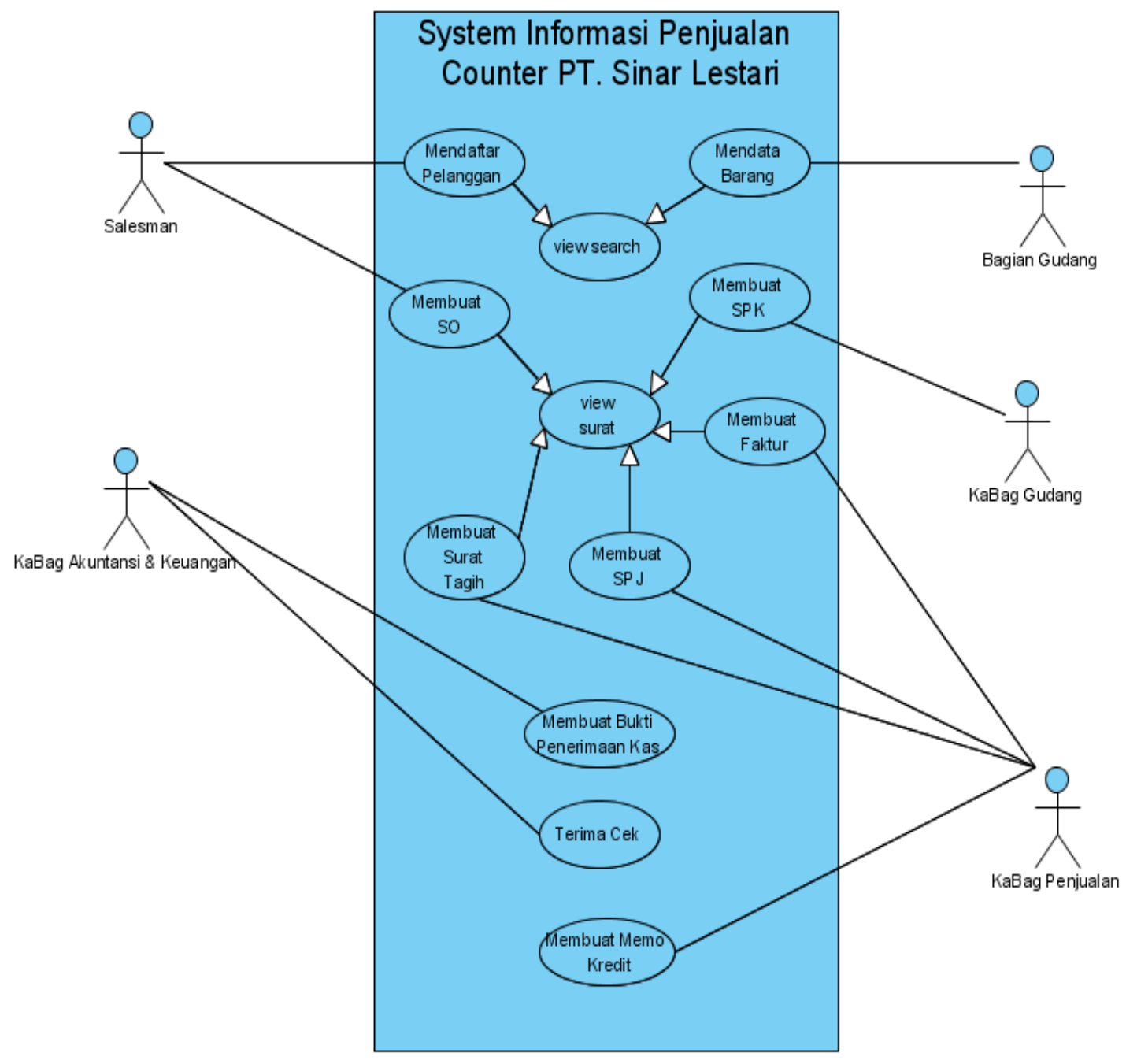

Gambar 1 Use Case Proses Penjualan dan Penerimaan Kas

Untuk penjelasan Use Case diatas, dapat dilihat pada Usecase Diagram Penjualan Counter Definition dibawah ini: 
Tabel 1 Definition Usecase Diagram Penjualan Counter

\begin{tabular}{|c|}
\hline Mendaftar Pelanggan \\
\hline $\begin{array}{l}\text { Pattern : Saat ada pelanggan yang ingin melakukan pemesanan, maka pelanggan harus terlebih dahulu } \\
\text { menjadi member, dan mengisi data, maka sales akan mendaftar pelanggan. }\end{array}$ \\
\hline Objects : Pelanggan, Sales \\
\hline Membuat Sales Order \\
\hline $\begin{array}{l}\text { Pattern : Pada saat pelanggan memesan barang, Sales akan membuatkan sales order yang berisi data } \\
\text { barang-barang yang di pesan oleh pelanggan yang selanjutnya akan diajukan kepada KaBag Penjualan. }\end{array}$ \\
\hline Objects : Pelanggan, Sales, KaBag Penjualan. \\
\hline Membuat Surat Perintah Kerja \\
\hline $\begin{array}{l}\text { Pattern : Pada saat menerima sales order dari sales maka selanjutnya KaBag Gudang membuat SPK ke } \\
\text { bagian gudang untuk mempacking barang sesuai SO. }\end{array}$ \\
\hline Objects : Sales, KaBag Gudang. \\
\hline Membuat Faktur \\
\hline $\begin{array}{l}\text { Pattern : KaBag Penjualan akan membuat faktur sebagai tagihan yang akan disertakan bersama dengan } \\
\text { surat perintah jalan kepada pelanggan. }\end{array}$ \\
\hline Objects : Pelanggan, KaBag.Penjualan \\
\hline Membuat Surat Perintah Jalan \\
\hline $\begin{array}{l}\text { Pattern : KaBag Penjualan akan SPJ sebagai surat bahwa barang yang dikirim sesuai dengan yang dipesan } \\
\text { pada SO. }\end{array}$ \\
\hline Objects : Pelanggan, KaBag.Penjualan \\
\hline Membuat Surat Tagih \\
\hline Pattern :KaBag Penjualan membuat surat tagih kepada pelanggan yang akan jatuh tempo. \\
\hline Objects : KaBag.Penjualan \\
\hline Membuat Bukti Penerimaan Kas \\
\hline $\begin{array}{l}\text { Pattern : KaBag Akuntansi \& keuangan membuat bukti pemasukkan kas untuk dimasukkan kedalam } \\
\text { database. }\end{array}$ \\
\hline Objects : KaBag Akuntansi \& Keuangan \\
\hline Terima Cek \\
\hline Pattern : KaBag Akuntansi \& keuangan menerima cek dan memasukan data kedalam database. \\
\hline Objects : KaBag Akuntansi \& Keuangan \\
\hline Membuat Memo Kredit \\
\hline $\begin{array}{l}\text { Pattern : KaBag Akuntansi \& Keuangan menerima laporan retur dari KaBag Gudang dan akan membuat } \\
\text { memo kredit untuk memotong piutang pelanggan berdasarkan faktur dan surat jalan retur yang didapat dari } \\
\text { pelanggan. }\end{array}$ \\
\hline Objects : KaBag Akuntansi \& Keuangan, Pelanggan, KaBag Gudang \\
\hline
\end{tabular}
XYZ.

Berikut adalah rancangan Class Diagram proses penjualan dan penerimaan kas pada PT. 


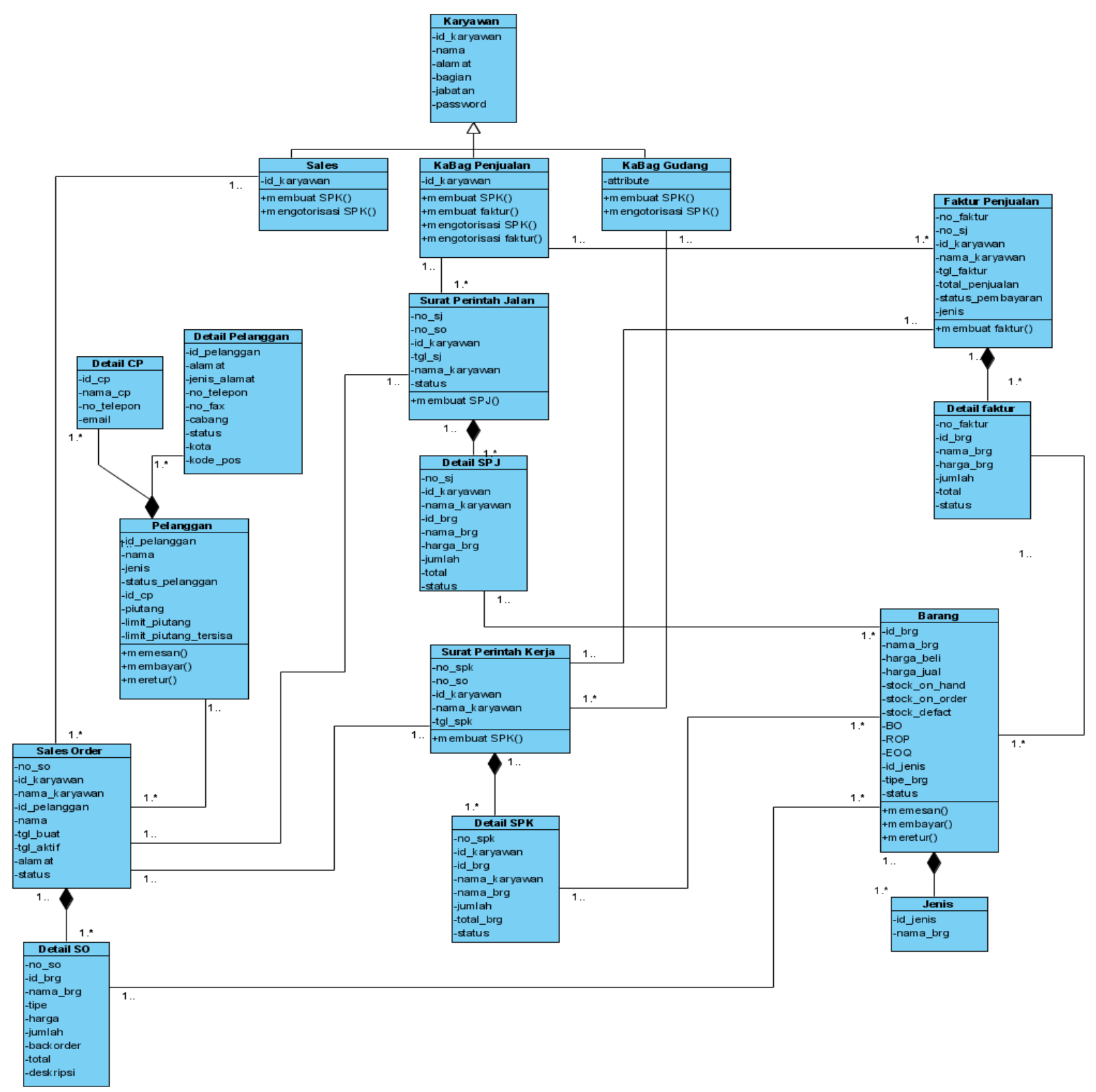

Gambar 2 Class Diagram Penjualan Non-Counter-Penjualan 


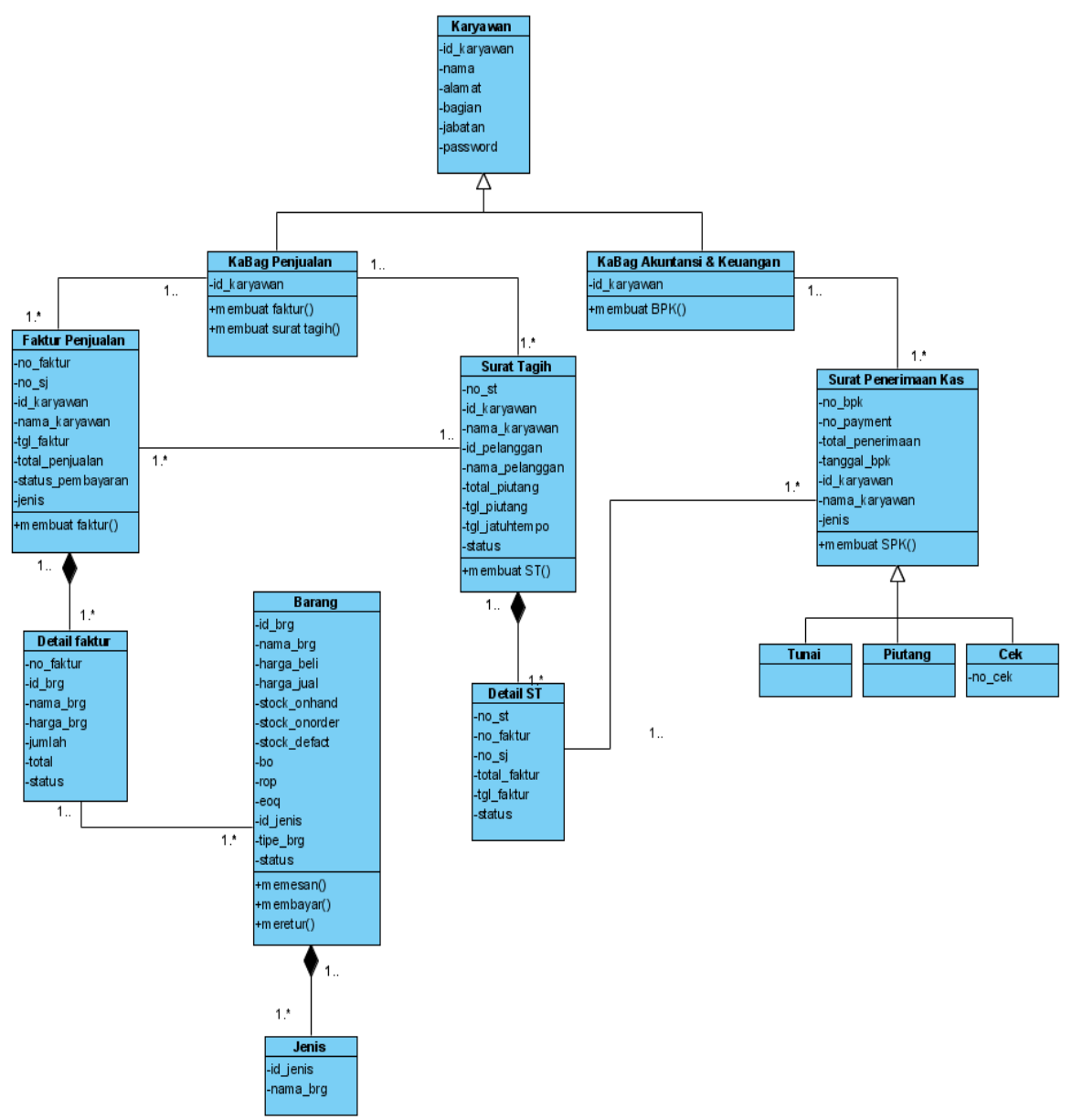

Gambar 3 Class Diagram Penjualan Non-Counter-Pembayaran

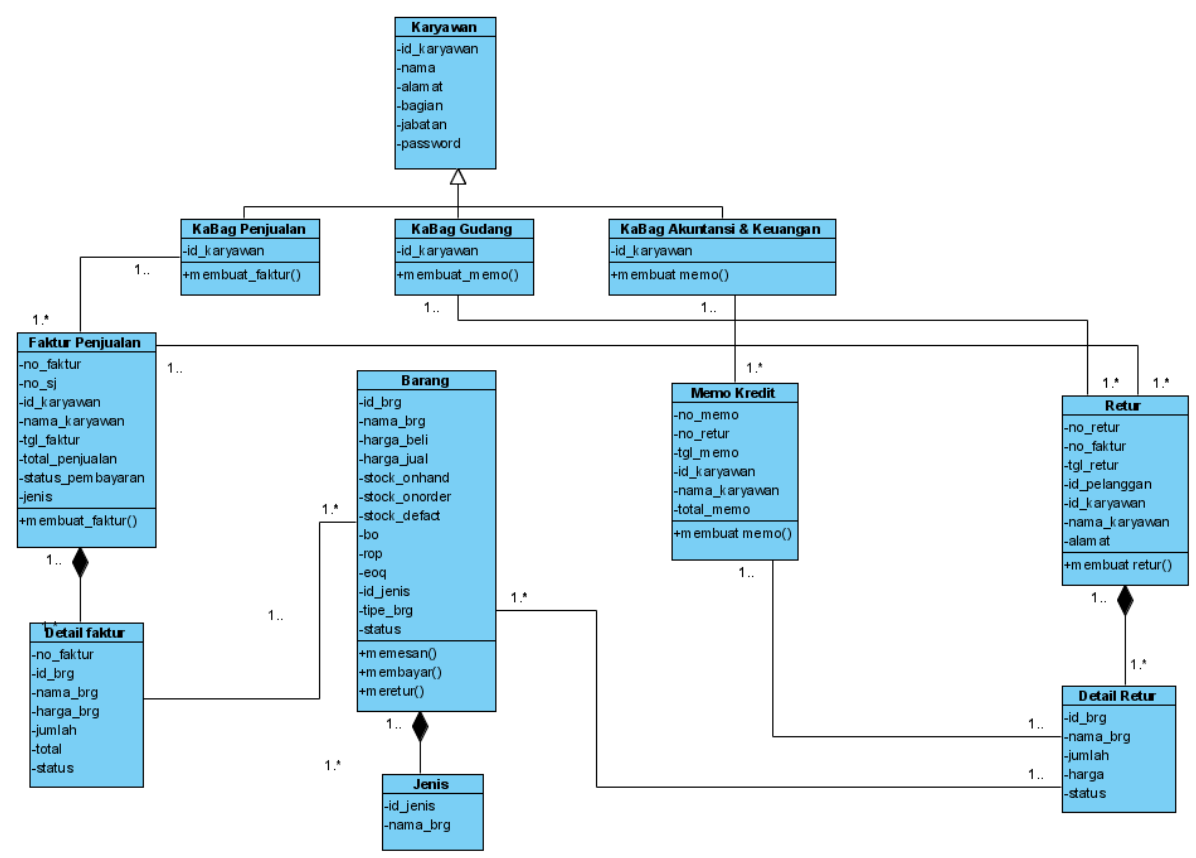

Gambar 4 Class Diagram Penjualan Non-Counter-Penjualan-Retur Penjualan 
Berikut adalah contoh UI proses penjualan dan penerimaan kas pada PT. XYZ.

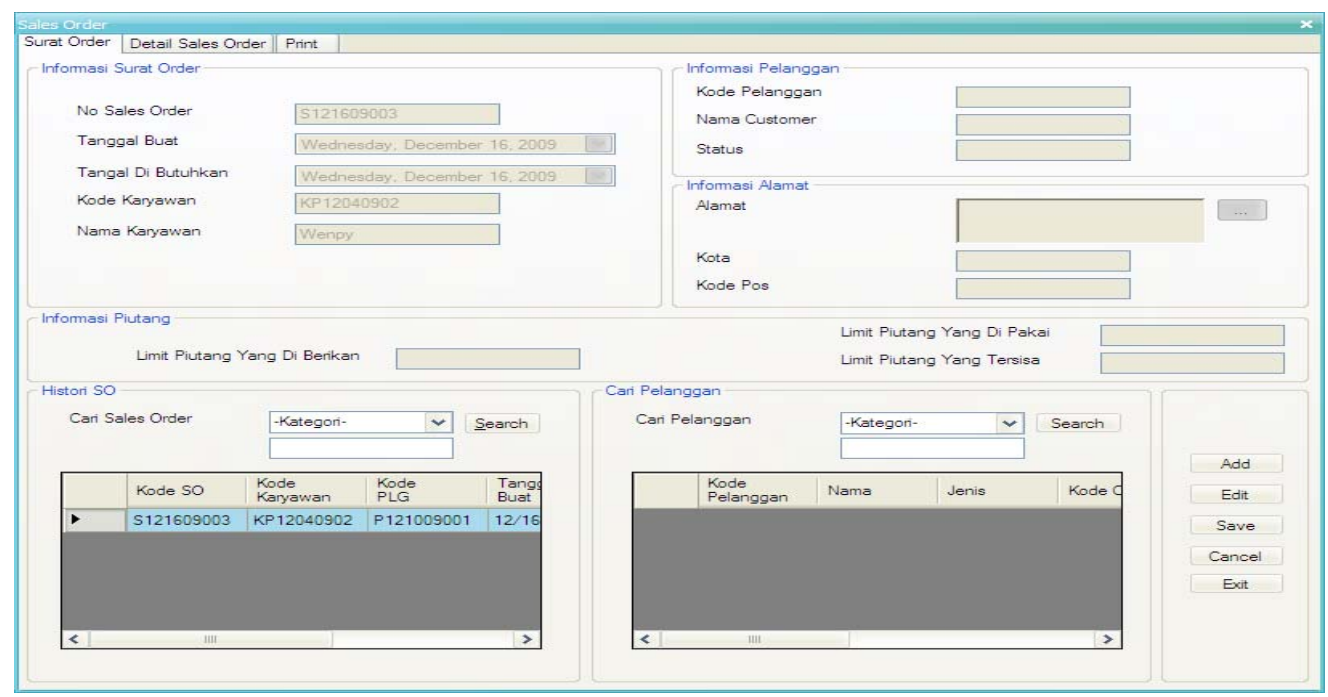

Gambar 5 User Interface - Sales Order

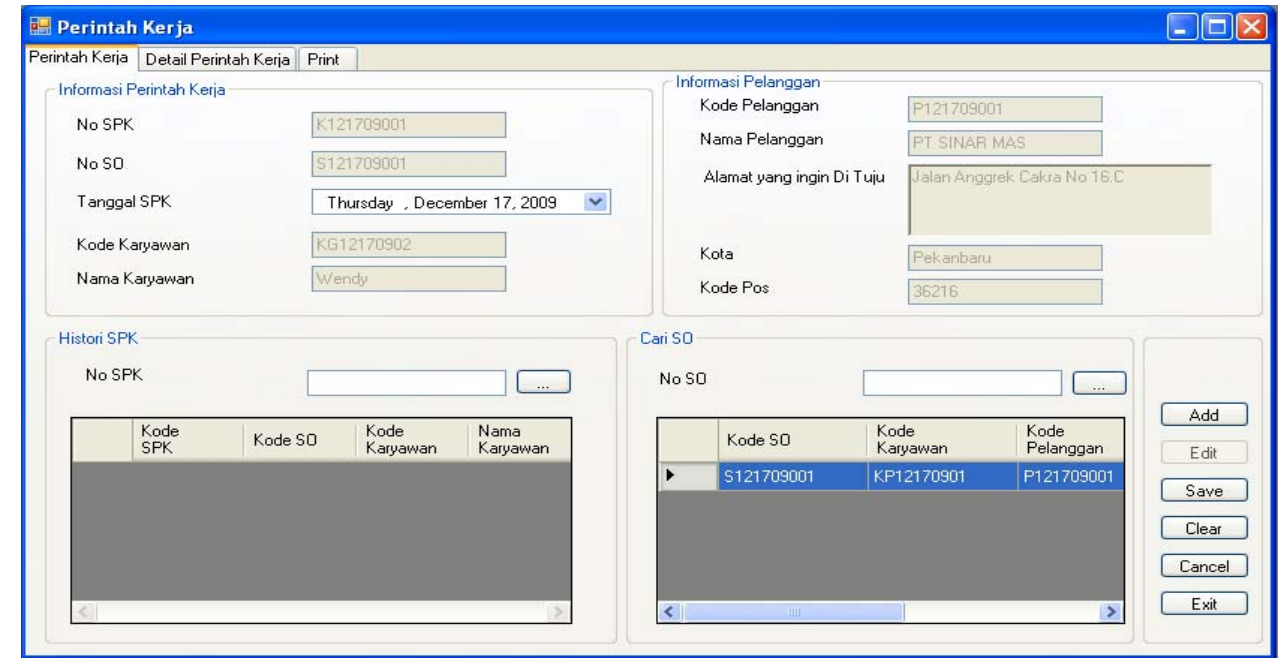

Gambar 6 User Interface - Perintah Kerja

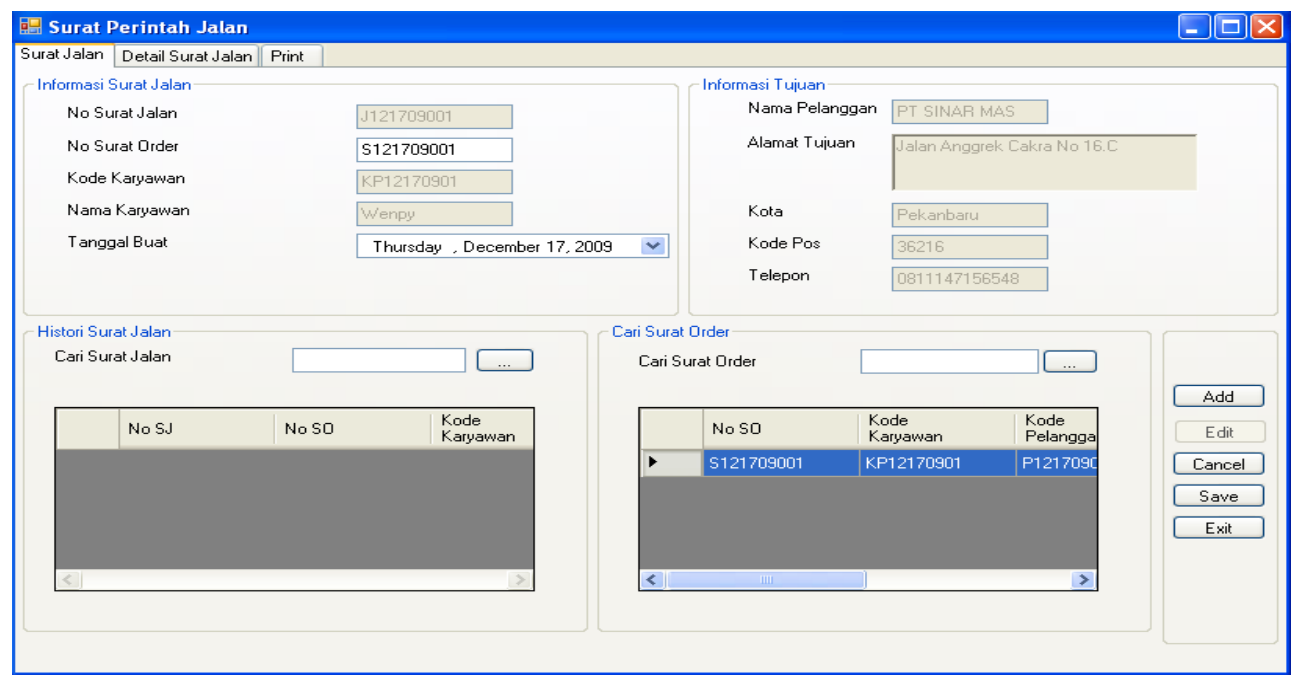

Gambar 7 User Interface - Surat Perintah Jalan 


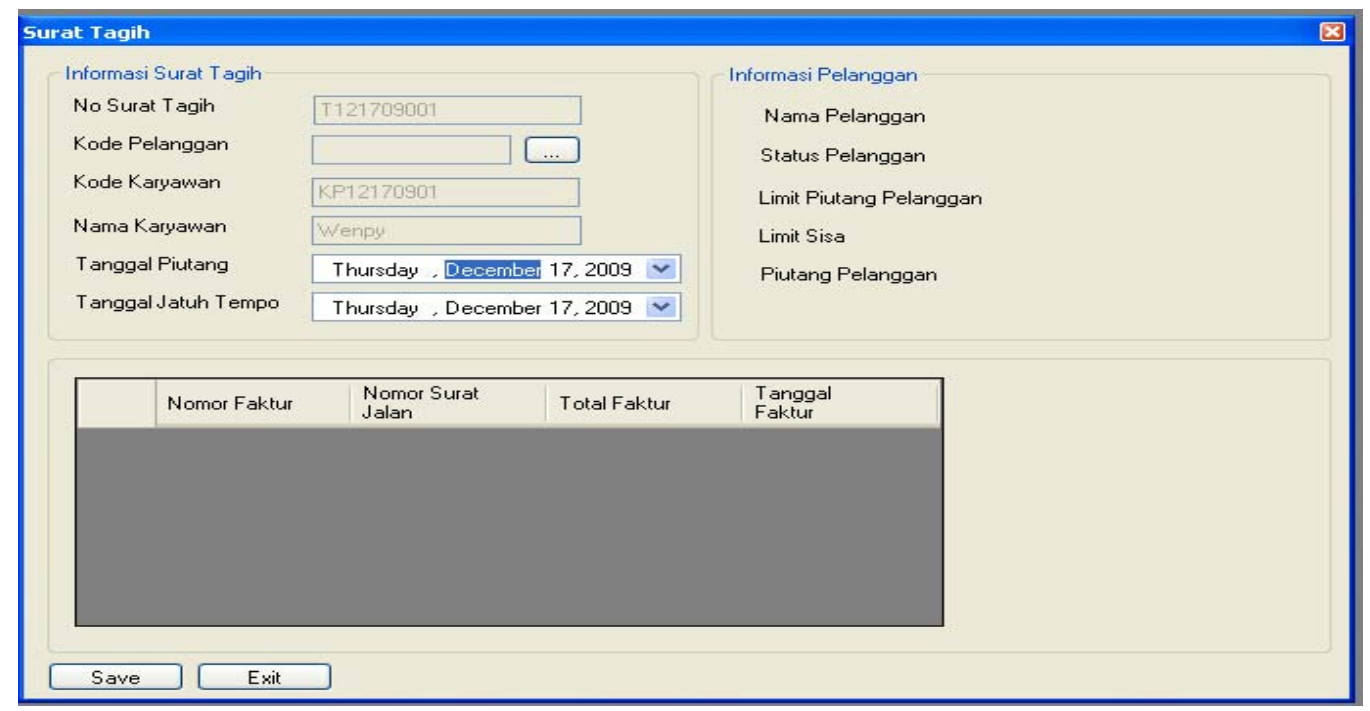

Gambar 8 User Interface - Surat Tagih

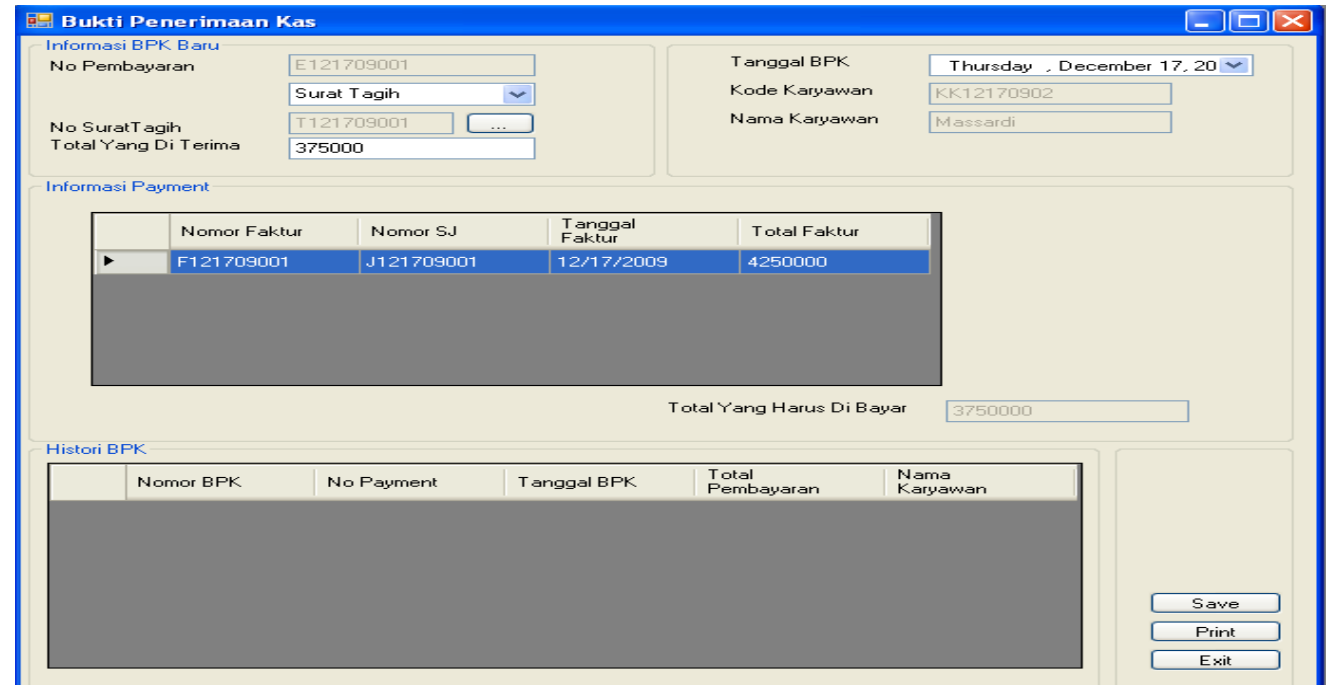

Gambar 9 User Interface - Bukti Penerimaan Kas

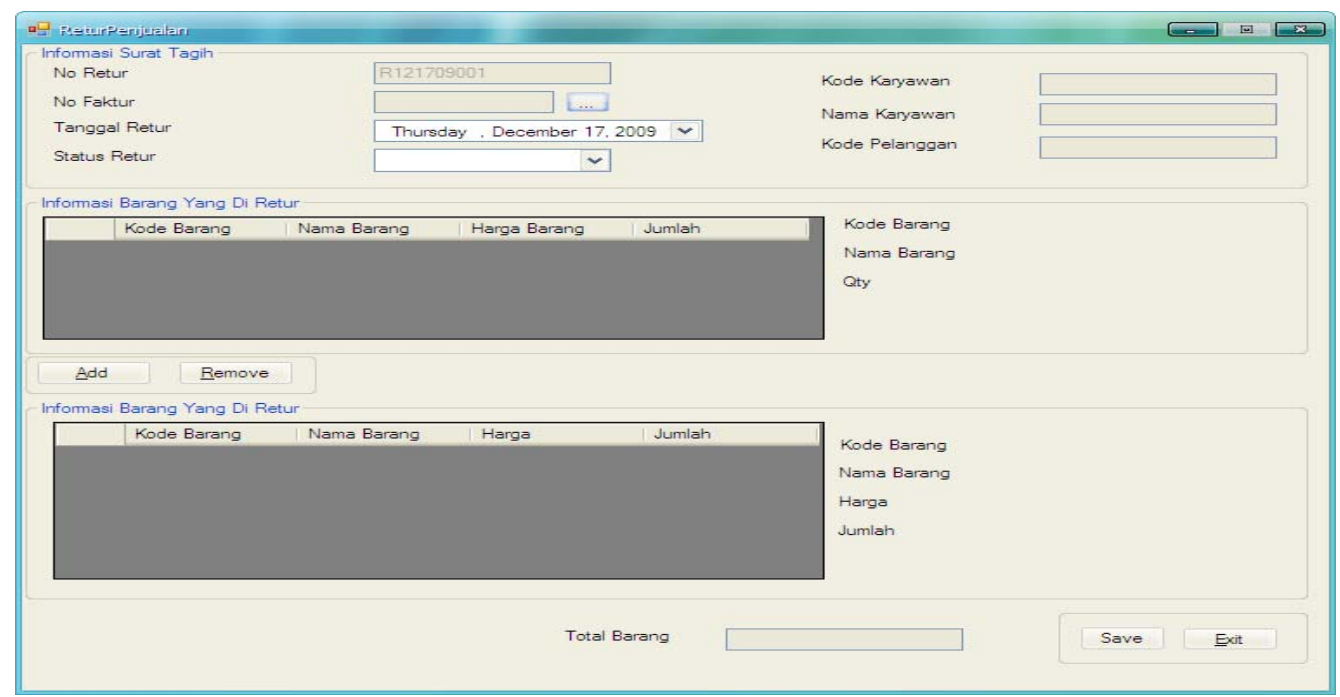

Gambar 10 User Interface - Retur Penjualan 


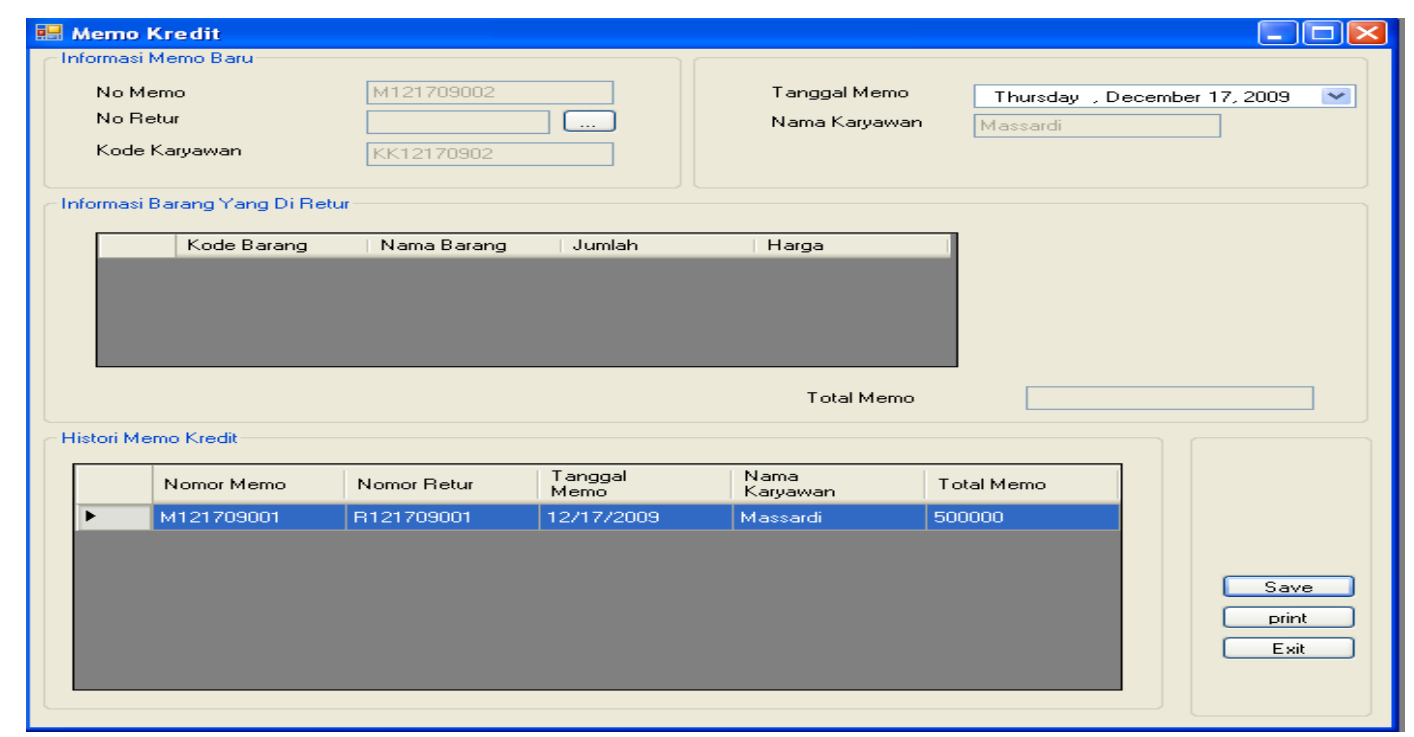

\section{Gambar 11 User Interface - Memo Kredit}

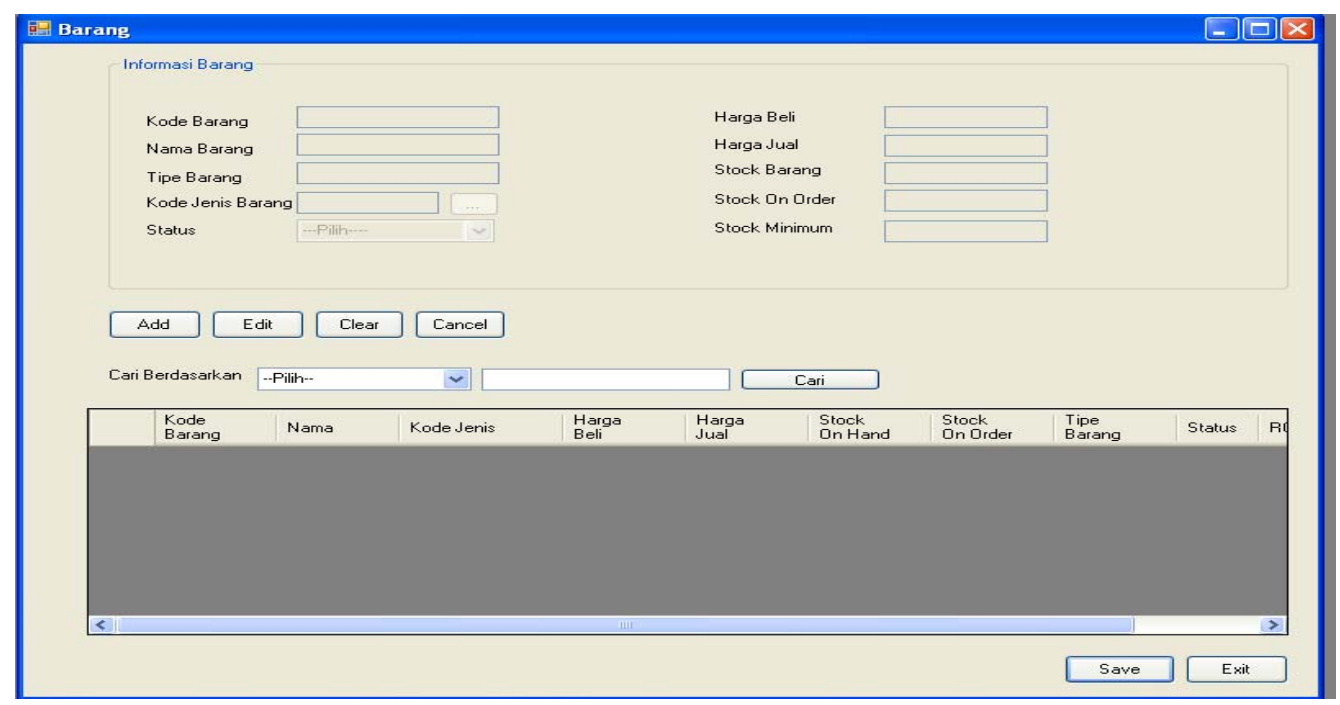

Gambar 12 UI Master Barang

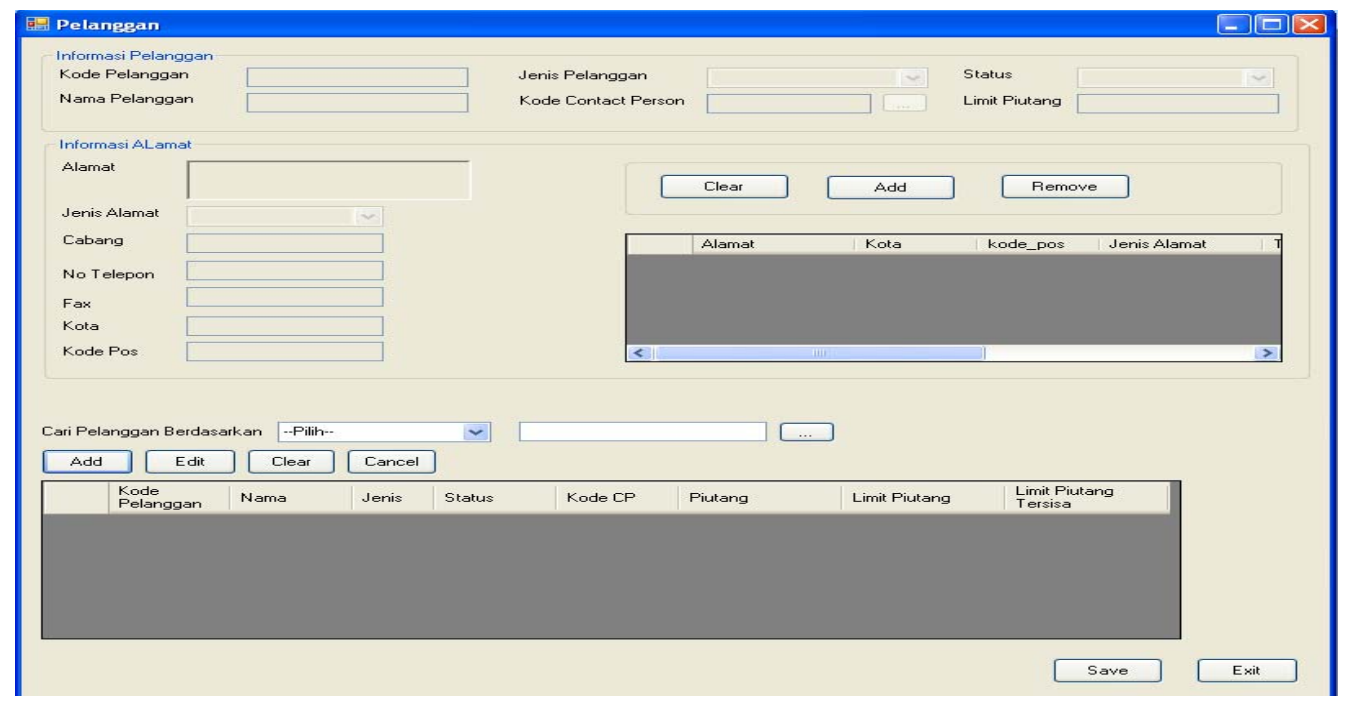

Gambar 13 UI Master Pelanggan 


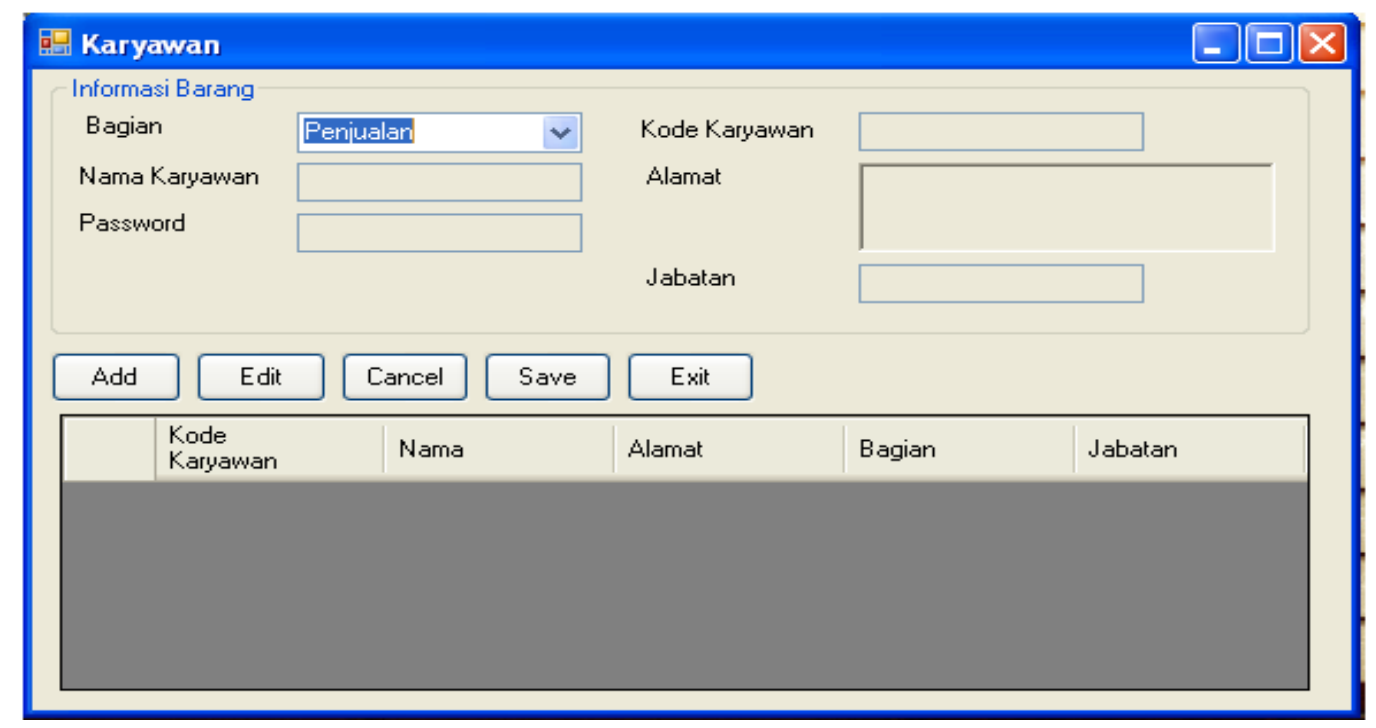

Gambar 14 UI Master Karyawan

Kegunaan dari sistem yang dirancang adalah untuk meningkatkan kinerja, menangani transaksi dan kegiatan dari toko dan meminimalisasi kemungkinan timbulnya masalah. Sistem ini juga dipakai untuk mengefisiensikan pelayanan kepada para pelanggan serta membantu karyawan dalam menjalankan operasionalnya atau tugasnya masing-masing.

Rancangan sistem yang baru akan dipresentasikan kepada toko sebelum diterapkan dan diharapkan toko dapat memahami kegunaan dari sistem baru tersebut dan dapat menerapkannya dalam kegiatan toko. Sistem baru tersebut akan diterapkan secara bertahap dalam pengimplementasiannya. Hal ini dimaksudkan agar toko dapat mempelajari sistem dan mengenalnya lebih baik, sehingga dapat menyesuaikan diri dengan sistem yang baru.

Penulis menggunakan beberapa tools seperti Microsoft Office Visio 2003 untuk mendesain UML Diagram, Microsoft Visual Studio (VB.Net) 2005 untuk mendesain dan memprogram UI, Microsoft SQL Server 2005 untuk mendesain database dan Crystal Report untuk pembuatan laporan.

\section{SIMPULAN}

Setelah menganalisa hal-hal yang berkaitan dengan penjualan dan penerimaan kas pada PT. XYZ, maka penulis memiliki beberapa kesimpulan. Aplikasi sistem informasi ini dapat membantu meminimalkan terjadinya kesalahan pencatatan data transaksi oleh karyawan, karena bila terjadi kesalahan-kesalahan dalam pencatatan data transaksi maka karyawan bersangkutan harus memberikan alasan atas kesalahan yang terjadi. Dalam hal meminimalisasikan kesalahan yang terjadi akibat kesalahan pencatatan data transaksi oleh karyawan, hal ini bertujuan agar setiap karyawan dapat lebih fokus dalam melaksanakan kegiatannya dan lebih bertanggung jawab atas segala tindakan yang dilakukan.

Untuk masing-masing bagian yang ada pada PT. XYZ memiliki wewenang dan tanggung jawab masing-masing, karena dalam hal ini masing-masing bagian terdapat hak akses yang berbedabeda dalam memperoleh informasi, sehingga masing-masing bagian memiliki suatu data kerahasiaan yang tidak dapat diketahui oleh bagian lain. Untuk bagian salesman, pihak bagian penjualan 
membutuhkan sebuah laporan data penjualan dimana laporan data penjualan tersebut dapat dijadikan sebagai tolok ukur bagi pihak penjualan untuk bisa menilai sales mana saja yang lebih produktif, sehingga dapat meningkatkan grafik penjualan dalam perusahaan. Dengan adanya sistem informasi akuntansi ini maka diharapkan dapat membantu pihak perusahaan dalam mengatasi permasalahan jangka pendek dan jangka panjang yang timbul terutama berkaitan dengan penjualan, penerimaan kas dan persediaan.

\section{DAFTAR PUSTAKA}

Jones, F. L., \& Rama, D. V. (2006). Accounting Information Systems (1st ed.). Canada: Thomson South.

Mathiassen, L., Munk-Madsen, A., Nielsen, P. A., \& Stage, J. (2000). Object Oriented Analysis \& Design (1st ed.). Denmark: Marko Publishing Aps.

Wilkinson, et al. (2000). Accounting Information Systems: Essential Concepts and Application (4th ed.). New York: John Wiley and sons. 